\title{
BACHELARD: REFLEXÕES PARA O ENSINO DE FILOSOFIA EM AGRONOMIA E VITICULTURA
}

\author{
GABRIEL K. DA ROCHA ${ }^{1}$; ANDERSON A. DA ROCHA ${ }^{2}$; JESSICA THAISE C. DA CRUZ ${ }^{3}$ \\ ${ }^{1}$ IF-Sertão PE. Doutorado em Filosofia pelo Pidfil UFPE-UFPB-UFRN. E-mail: gkafure@gmail.com \\ ${ }^{2}$ Bacharelado em Agronomia do Instituto Federal do Sertão Pernambucano, Campus Petrolina Zona Rural \\ ${ }^{3}$ Estudantes do Curso Tecnológico de Enologia e Viticultura do IF-Sertão PE \\ Artigo submetido em Abril/2016 e aceito em Setembro/2016
}

\section{RESUMO}

O presente artigo pretende fazer um relato acerca do ensino da disciplina Filosofia no âmbito dos cursos de Agronomia e Enologia do Instituto Federal do Sertão Pernambucano. Por meio de um estudo mais aprofundado da recepção das obras de Bachelard nas diversas ciências, foi possível entender que é possível uma ontogênese de uma epistemologia dessas ciências agrárias também. François Dagognet, que valendo-se de ser um dos principais discípulos de Bachelard, criou toda uma epistemologia das ciências da terra, como também escreveu importantes escritos para a Agronomia no seu livro Des revolutions vertes que envolvem questões como a relação da própria filosofia com a agroecologia. Já no caso da Viticultura e Enologia, Bachelard, em seus diálogos com o parceiro intelectual Gaston Roupnel, em Terra e devaneios do repouso, escreveu sobre as relações do vinho com a alquimia. Um importante estudo que resgata aspectos das ciências que foram esquecidas e negadas pela ciência moderna. Ora, nesse sentido, o presente escrito tem um vasto arcabouço para dialogar essas possibilidades de expansão dos limites e fronteiras da própria filosofia no contexto do ensino técnico.

PALAVRAS-CHAVE: Bachelard. Campos. Vinho. Técnica.

\section{ABSTRACT}

This article intends to make a report on the teaching of philosophy discipline within the Agronomy and Enology at the Federal Institute of Sertão Pernambucano. Through further study of the reception of the works of Bachelard in the various sciences, it was possible to understand that it is possible to ontogenesis of an epistemology of these agricultural sciences as well. François Dagognet that taking advantage of being one of the main disciples of Bachelard, created a whole epistemology of the earth sciences, also wrote important writings for Agronomy in his book Des revolutions vertes involving issues such as the relationship of philosophy itself with the agroecology. In the case of Viticulture and Enology, Bachelard, in his dialogue with the intellectual partner Gaston Roupnel on La terre et les rêveries de la volunté, wrote about the wine's relationship with alchemy. An important study that rescues aspects of science that have been forgotten and denied by modern science. Now, in this sense, this writing has a broad framework for dialogue these possibilities of expansion of the limits and boundaries of philosophy itself in the context of technical education.

Keywords: Bachelard. Fields. Wine. Technics. 


\section{CONSIDERAÇÕES INICIAIS}

A questão da técnica é sempre uma problemática filosófica importante, já que sua ambiguidade leva sempre a dois lados, duas razões que se contradizem: uma gira em torno do pensamento mais reflexivo e a outra em torno da inteligência pragmática. Ora, o problema está justamente em se entregar à técnica, deixar que ela pense por nós e não ter a capacidade de dizer "não" a essas tecnologias. Nesse sentido, Gaston Bachelard, epistemólogo da Filosofia do não, da reflexão dos princípios que regem o conhecimento e da importância do pensamento a posteriori sobre a ciência e, consequentemente, a técnica. Isso faz com que podendo nos dar uma contribuição vantajosa para pensar essa questão e colocá-la no contexto das ciências agrárias, Bachelard seja justamente um filósofo pouco trabalhado e conhecido no âmbito do pensamento rural, mesmo que ele, tenha sido, paradoxalmente um camponês nascido na região de Bar-sur-aube na França.

Para abrir caminho dessa reflexão, é preciso admitir que Bachelard pode ter confundido agronomia e agricultura, assim como as pessoas costumam confundir ecologia e meio ambiente, ou mesmo epistemologia com filosofia das ciências. Essa confusão, que se esclarece na medida em que há um aprofundamento em cada um desses campos de saber, coloca em pé a questão de que será que é possível com a teoria de Bachelard definir um domínio do conhecimento como a Agronomia e/ou Enologia?

O primeiro aspecto nesse empreendimento é compreender a realidade relacional entre essa ciência da ação e pela ação, ou seja, da produção e dos produtores, respectivamente. Ora, mas onde Bachelard entra aí? Ele justamente pode contribuir para identificar os obstáculos epistemológicos que estão entre a produção e os produtores e com isso delinear que há também outros aspectos da complexidade das ciências que podem ser complementados pela fenomenologia.

A contribuição da noção de obstáculo epistemológico que enfatiza que, em agronomia, é considerado como um racionalismo aplicado às "experiências" conjugadas sempre é, de maneira inseparável de dois <experimentadores> ao menos: o agricultor e o engenheiro agrônomo. (HERVÉ, 1997, p. 67).

Essa experiência primeira, ao ver de Bachelard, não é de nenhum modo segura, e, por isso, justifica a formação e uma ciência que vá além dos obstáculos intuitivos e verbais ${ }^{1}$ do produtor rural. Contudo, o próprio agrônomo ou enólogo, não pode ir totalmente contra as relações metodológicas de produção, que determinam o estado de fertilidade da terra. Pois justamente os erros e obstáculos da própria agronomia, podem ter levado, num passado, à infertilização de terras extenuadas pelo agronegócio.

\footnotetext{
${ }^{1}$ Obstáculos verbais e intuitivos, do ponto de vista descontínuo da obra diurna bachelardiana, querem dizer que há uma tendência associativa entre palavras concretas e abstratas. Essa situação demonstra que certas palavras são tão explicativas que funcionam imagens que substituem explicações. Esse obstáculo não é algo que pode ser eliminado, ele sempre acompanhará o conhecimento e precisa até ser aceito em um determinado ponto artístico e imaginário.
}

Dialektiké, v. 2, 2016. p. 10-18 
O jogo de representação entre produtores e cientistas se cruzam entre diferentes escalas do espaço e tempo. Na Formação do espírito científico (publicada originalmente em 1938), Bachelard (1996, p. 113) alega que o obstáculo da unidade pragmática é "um dos obstáculos epistemológicos relacionados com a unidade e poder atribuído à Natureza é o fator realidade que atribui à mente científica tudo que é natural". Eis que a relação entre seres vivos e processos de produção econômicos nas ciências agrárias, em geral, têm a necessidade de uma perspectiva de ecologia na produção e uso da terra, pois, em outras palavras, a natureza (physis) é o meio de onde nascem todas as ciências invariavelmente. Mesmo que para Bachelard, a matemática seja a matriz da ciência, ainda assim, a sua aplicação à economia e à própria natureza fazem com que as ciências agrícolas sejam ciências relacionais. ${ }^{2}$

Segundo Dagognet, numa concepção tida como realista e complexa, que ele escreveu em 1973 em seu livro As suas revoluções verdes, tendo como objeto o que se entende como Agronomia sendo uma "disciplina subversiva", ligada essencialmente à observação dos paradigmas e consequências da modernidade agrícola como:

A ciência que alguns filósofos têm considerado neutra, estritamente material e única provedora de meios, sabe-se aqui na realidade, que suas estruturas mais antigas conseguem impor um novo propósito, uma vez que disso exige-se grandes grupos com a tarefa de fabricação. Ela foi confiada primeiro em mãos especiais como única maneira de quebrar as técnicas rudimentares e feudais bloqueadas. [...] Deixando agora aos proprietários que o formalismo dos seus títulos, [consiste] numa ligeira vantagem que vai continuar a evaporar-se. (DAGOGNET, 1973, p. 169 - grifos nossos).

A seguir, partiremos então, para a reflexão sobre essa relação da filosofia de Bachelard e das ciências agrárias como uma busca epistemológica desses fundamentos de neutralidade e materialidade da ciência. Os textos que se seguem foram parte dos textos produzidos por estudantes das ciências agrárias do Instituto Federal do Sertão Pernambucano complementadas por comentadores sobre a questão.

\section{BACHELARD E A AGRONOMIA}

Sem dúvida, não é por falta de apego à terra. Muito pelo contrário, pareceu-me que seria trair o pomar e jardim do que falar deles num curto capítulo. Seria preciso um livro inteiro para discorrer sobre a agricultura imaginária, as alegrias da enxada e do ancinho (BACHELARD, 2001, p. 12).

Os processos produtivos agrários foram responsáveis, através dos tempos, por grandes transformações da humanidade, desde os primórdios em que o homem se

\footnotetext{
${ }^{2}$ As nuances de uma possibilidade relacional do conhecimento desvelam uma metodologia dialética flexível que busca entender a relação entre os componentes de um fenômeno. Isto é, justamente abarcar o ser da realidade como conjunto de possibilidades.
}

Dialektiké, v. 2, 2016. p. 10-18 
reconhece como ser dependente da natureza, necessitando retirar dela alimento para a sobrevivência e continuidade da espécie. Evoluindo para as primeiras técnicas de cultivo quando a necessidade de formação das primeiras sociedades onde o homem, que até então era nômade, começa então a se estabelecer em territórios fixos, é aí que ocorre diversas alterações na cadeia produtiva vegetal, cenário onde atua com maior força a agronomia.

Antes da primeira guerra mundial, a agronomia era tida e vista como ramo de atividade pragmático, que tinha como principal função extrair do solo o sustento basicamente familiar sem levar em consideração as constituintes do complexo cenário que forma a cadeia produtiva vegetal. Utilizava-se a visão única de que o solo e os minerais necessários para o crescimento dos vegetais eram suficientes para a grande tarefa de saciar a fome do homem.

Com o fim da primeira guerra mundial, evidenciou-se a necessidade de produção e fornecimento de grande quantidade e diversidade de alimentos para os países que dizimados pela guerra estavam impossibilitados de importar ou produzir alimento, esta urgência desencadeou um processo de aceleração no processo de produção. A ciência naquele momento, ainda que timidamente, começava de fato a assumir o papel de desenvolvedor de técnicas e produtos que fossem capazes de garantir a alimentação para a população da época.

Baseado na teoria relativista da matéria de Einstein, que procurava romper com as teorias clássicas absolutistas, principalmente coma teoria absolutista de Newton, Bachelard lançou um profundo olhar sobre a epistemologia. A geração, na esfera agronômica, de uma tal realidade epistemológica, não aceita mais a definição do objeto absoluto, radical, por não permitir espaço para devaneios humanos. Essa esfera é também necessária nas entrelinhas das compreensões científicas, que já eram limitadas para o universo agrário da época e que hoje continuam vistas de maneira positivista. ${ }^{3}$

Segundo Bachelard, não se concebe a figura do agricultor e do agrônomo como sendo uma só, suas indagações epistemológicas diferenciavam tais figuras, partindo do princípio que a ciência agronômica por si só não se sustenta. A possibilidade da agronomia beber na mesma fonte das ciências químicas e biológicas, faz com que, também, se construa um panorama mais amplo de possibilidades evolucionistas de produção.

O pleno conhecimento do solo não só como meio de sustentação vegetal e animal, mas como agente modificador eleva potencialmente as condições de produção. $O$ estudo detalhado, não só dos elementos químicos, mas também, de suas formas de disponibilidade para os vegetais, bem como o reconhecimento da água e da matéria orgânica como veículos facilitadores dos processos de transformação, coloca nossa sociedade frente a uma nova realidade agronômica. Com base nestas evidências, Bachelard fundamenta a distinção proposta de que o agrônomo e o agricultor são figuras distintas, contudo, inter-dependentes entre si. A partir de então, abre-se um vasto leque de possibilidades, as mais diferentes regiões do planeta agora têm em mãos condições de testar novas formas de cultivo não se

\footnotetext{
3 Bachelard, apesar de ter características positivistas em sua obra, por um próprio contexto cultural e acadêmico da época, acaba traçando uma ruptura com o mesmo, no próprio plano em que enquanto o positivismo queria desclassificar o aspecto metafísico da ciência, Bachelard retoma a metafísica como possibilidade conhecimento a posteriori da ciência.
}

Dialektiké, v. 2, 2016. p. 10-18 
limitando a cultura ou ao ecossistema, levando cada vez mais tecnologia às diversas regiões do planeta.

Essa fundamentação necessita de um moderador, pois, a corrida na revolução da produção, eleva o risco de utilização sem precedentes de diversos compostos químicos o que acarretaria em um desequilíbrio ambiental imenso, Bachelard conduz sua linha filosófica baseada na epistemologia, estudo dos problemas que se relacionam com o conhecimento humano, o que obriga a uma reflexão sobre a sua natureza e validade, a fim de abrir caminho para o que podemos chamar de agricultura ecologicamente correta.

Como adepto da simplicidade, Gaston Bachelard mantinha uma relação estreita com o campo e com a natureza. Viu de perto os horrores da primeira grande guerra, formouse em Matemática e, posteriormente, se pós graduou em Filosofia das Ciências, chegando a se tornar professor da Sorbonne. Ou seja, reuniu o conhecimento e a experiência pessoal necessários para um maior entendimento das questões antropológicas e científicas da época. Não diferentes estes valores estão contidos dentro da realidade agronômica que conhecemos hoje em dia, graças a sua inquietação acadêmica e moral, que nos possibilita enquanto agrônomos a reflexão e a busca incessante de cumprir a nobre tarefa de garantir a produção de alimentos para a humanidade, margeados sempre pela sombra da prudência epistemológica de Gaston Bachelard. Não poderia ser diferente, a intimidade de Bachelard com as questões rurais, frente a tão fortes evidências de pontos em comum, a realidade e o pensamento responsável, calcado em valores inovadores.

Como produto dessa reflexão, nada melhor do que se voltar à realidade, em que é possível remeter as leituras sobre Bachelard nesse campo:

Durante um programa na televisão francesa que foi dedicado a Bachelard [...], o velho homem estava no meio de seus livros, suas deliciosas cebolas frescas e legumes crus que ele comprou do mercado Mouffetard (onde gerações de estudantes agrônomos da rua Claude Bernard descobriram os produtos da terra e de toda a Terra). Ele disse ser um homem feliz por caminhar pelos mercados de bairro, imagens de um campo na cidade. Ele saboreia os cheiros e sabores do pão, queijo e vinho, arquétipos de alimentos permanentes. Em alguns aspectos, e sem querer, ele abre a aventura de uma psicanálise dessas imagens. (HERVÉ, 1997, p. 62)

Nesse sentido, passaremos agora da psicanálise da imagem do vinho para a enologia, uma tarefa que terá uma ruptura epistemológica, como poderá ser observado, em que a linguagem do filósofo passará do diurno (epistemológico) para o noturno (imaginário), de uma maneira complementar.

\section{BACHELARD E A ENOLOGIA}

O filósofo Gaston Bachelard tinha seu pensamento focado principalmente em questões referentes à filosofia da ciência. Bachelard formula suas principais proposições para a filosofia das ciências: a historicidade da epistemologia e a relatividade do objeto. $E$ 
podemos observar algumas das características do filósofo em alguns trechos escritos pelo mesmo.

\begin{abstract}
As belas matérias: o ouro e o mercúrio, o mel e o pão, o azeite e o vinho, acumulam devaneios que se coordenam tão naturalmente que é possível descobrir-se neles leis de sonho, princípios da vida onírica. Uma bela matéria, um belo fruto, nos ensina frequentemente a unidade de sonho, a mais sólida das unidades poéticas. (BACHELARD, 2001, p. 249).
\end{abstract}

No artigo "Como Beber uma metáfora", Domique Lecourt, discípulo de Althusser, que resgatou o pensamento bachelardiano dentro do contexto pedagógico, no presente contexto de Bachelard e a unidade poética, ele esclarece que o aspecto noturno de Bachelard, ao refletir sobre a importância dos alquimistas nas concepções psíquicas e

Do conceito da metáfora de Bachelard, o filósofo da ciência irá realizar uma desconfiança comum ou mesmo hostil. [...] O pensamento de Gaston Bachelard permite interpretar facilmente e armazenar a órbita das filosofias racionalistas tradicionais. O dinamismo da produção de conhecimento, o tom racional, opõe-se à preguiça da imagem fixa, [mostra um] complexo estruturado. (LECOURT, 1997, p. 12 - grifos meus)

Essa é justamente a justificativa para essa passagem da metáfora como obstáculo, ou seja, como erro da intuição, que será ativamente construtor da retificação de um conhecimento mais amplo e complexo. A metáfora, vista do ponto de vista poético e onírico, tem a sua riqueza justamente na possibilidade de deformação da realidade, e é no vinho e em outras substâncias que os alquimistas viam a própria possibilidade de transmutação da matéria.

Seguindo nesses trechos que ele mostra como algumas matérias, assim como o vinho, são mais que uma ciência, são manifestações do imaginário que ajudam a mostrar que esta não é uma simples bebida, que ela tem uma história por trás e que deve ser apreciada.

Por ser a videira a rainha do reino vegetal, e o vinho o seu subproduto mais admirado, chega o momento no qual o vinho se compara com o sangue que é o líquido nobre que move o reino animal e ao ouro que é o líquido mineral de alta nobreza. Eis que chega haver questionamentos que circulam em torno dos mistérios do vinho, das nuances que ele consegue obter que vai do vermelho ao dourado. Mostrando mais uma vez como um vinho pode e deve ser também algo místico a ser desvendado.

Por reter poucos vestígios da terra: é por tais qualidades que ela tem a virtude de curar todas as doenças do homem, quando bem preparada, e de aumentar-Ihe o calor. Sendo universal, ele aquece um temperamento úmido e frio, e refresca um temperamento quente e seco. (BACHELARD, 2001, p. 254). 
Ele também mostra as qualidades do vinho para saúde humana, assim como fala sobre as sensações que podem ser causadas ao ser degustado, do tinto que aquece e do branco que refresca. Sapere aude, o saborear do vinho é como saborear o saber, transformar chumbo em ouro, é como transformar a ignorância em sabedoria.

Para Roger Vernon Scruton, um filósofo e escritor inglês cuja especialidade é a Estética, dentro de outro contexto diz:

O vinho, bebido adequadamente, transfigura o mundo para qual olhamos, iluminando o que é precisamente mais misterioso nos seres contingentes que nos cercam: o fato que eles são - e também que eles podem não ser. (SCRUTON, 2011, p. 67)

Não só o vinho, mas qualquer outra bebida alcoólica deve ser bebida adequadamente, para que não cheguem ao estado de embriaguez. Se a pessoa tem consciência do seu limite e consegue degustar a bebida sem se embriagar poderá desfrutar de bons pensamentos, poderá, de certa forma, conhecer melhor as pessoas e até mostrar-se de uma maneira mais verdadeira e aberta. Como alguns costumam dizer que: quando se bebe, muitos falam o que realmente pensam. Assim, também, deve ser o processo educativo: falar o que se pensa com eloquência e educação; não ter medo de pensar, pois isso é a própria tarefa da filosofia.

Em uma degustação de vinho, é na primeira taça que você conhece todas as suas qualidades e defeitos. Sugestão: $O$ conhecimento do vinho também é obtido utilizando-se todos os sentidos humanos, como, por exemplo, pela visão pode-se afirmar se ele é um vinho jovem ou um vinho envelhecido/de guarda, se tem algum defeito (por conta da sua limpidez, se há turvações ou precipitações). Como num primeiro encontro, ou até mesmo num primeiro olhar para alguém, já é possível detectar algumas características e qualidades dessa pessoa, assim acontece, também, com o vinho. E por muitas vezes, é essa primeira impressão a que fica, tanto para o vinho como para pessoas, bem como a impressão da qualidade da filosofia, de acordo com a aproximação com o saber com que ela dialoga.

Quando se tem uma memória aguçada para aromas e sabores, por muitas vezes, degustar um vinho pode nos remeter a várias boas recordações, que podem ir desde a infância até a fase adulta. Como exemplo, um determinado aroma pode nos fazer lembrar de alguma coisa boa da nossa infância e isso pode nos levar ao inebriamento e fazer com que aquele determinado vinho faça parte da nossa história e que sempre que se queira sentir ou reviver essa sensação/momento pode-se procurar degustá-lo. Para Bachelard, essa relação com a memória e o aroma geram a própria ontologia do odor, a duração da memória é onde perdura a possibilidade de permanência da própria experiência do pensar filosófico.

No decorrer dos estudos realizados, a filosofia se mostra como muito importante para vida, por fazer refletir e observar pontos que por muitas vezes acabam passando despercebidos. E para Enologia, acaba até se tornando uma aliada, por mostrar que beber/degustar um vinho vai além de somente ingerir a bebida e é um momento de prazer, de inebriamento, de sensações e vivências que tornam a bebida bem mais saborosa. Beber a filosofia é quando se consegue aproveitá-la na sua degustação e que devemos conhecer os 
nossos limites para que assim, possamos evitar o estado de embriaguez (o delírio e a ilusão que a mídia e os meios de informação tendem a incentivar), para não perdemos a consciência dos nossos atos. E esse é um dos poucos, mas também, maiores ensinamentos que puderam ser adquiridos por meio das aulas de filosofia:

Então Bachelard e vinho? Sim, e por que não? Uma vez que outros textos famosos nos convidam a isso também; mas desde que você não veja, neste contexto, o que indica um pensamento bucólico que seria lento e felizmente subserviente aos aforismos do sentido. Bachelard não é um homem das irmandades. E é sem dúvida, um daqueles filósofos para quem beber vinho é uma declaração significativa, não apenas um gesto de prazer, é acima de tudo o filósofo do pensamento solitário, tendendo para a reconciliação impossível de lucidez e da vontade, a este lugar impensável, em que a razão e imaginação convergem. (LIBIS, 1997, p. 28)

Por fim, como o próprio Bachelard diz, a capacidade de saborear um vinho verdadeiramente, é como um universal que torna-se singular, ora, nesse processo de transmutação, assim como a uva se torna em bebida, o saber (universal) se torna experimentado (particularizado) e vivido por aquele que ousa unir e conciliar a impossibilidade da lucidez e vontade, razão e imaginação por meio de Bachelard na própria educação.

\section{NOVAS PAISAGENS EDUCATIVAS PARA A FILOSOFIA DAS CIÊNCIAS AGRÁRIAS}

Nota-se facilmente que há uma grande diferença entre a reflexão das perspectivas de um pesquisador (Bacharel) em Agronomia e uma tecnóloga em Enologia. Tal diferença foi provocada propositalmente para que os aspectos diurnos (epistemológicos) e noturnos (imaginários) de Bachelard fossem evidenciados como complementaridade do próprio espírito científico presente na cultura acadêmica.

Sabe-se que Bachelard leu a obra A história do campo francês de Roupnel e que a influência dessa obra foi muito grande entre os estudiosos agrários da época. Nesse sentido, este artigo foi traduzindo textos (contudo, por ser um campo de investigação ainda pouco explorado no Brasil, é necessária uma política de adquirir e traduzir livros que só existem na França atualmente) que dão conta principalmente de um aprofundamento de pesquisas reflexivas do curso tecnológico como Enologia e Viticultura, para o ensino da disciplina Filosofia e Ética. É interessante que,

É evidente que o campo da videira foi sobreposto ao território agrário primitivo; em todos os lugares, o que se manifesta é como um anexo tardio acrescentado ao país de origem e sem harmonia com a mesma. [...] as videiras reúnem o efeito destas encostas íngremes, encostas rochosas sobre aquelas que foram deixadas para a floresta na distribuição original da terra, que pertencia por direito à natureza livre." (ROUPNEL, 1932, p. 189) 
Investigar essa transposição de culturas e terras, essa dita desterritorialização no contexto de novas regionalidades mostra como a revolução agrícola transformou a técnica em potencialidades de transformação que precisam ser refletidas dentro do contexto do nomos e do caos da natureza. É preciso persistir na investigação do que é a dita natureza naturante e naturada. ${ }^{4}$

Bachelard coloca a superação do obstáculo quantitativo pelo qualitativo no contexto agrário por perceber que as ciências agrárias devem ser revolucionárias e "mais subversiva do que outras técnicas porque ela transforma o que é quase imutável e sagrado: paisagem, terra, gestos antigos, comida, o pão e o vinho " (DAGOGNET, 1973, p. 163)

De fato, a experiência da verdadeira imersão da filosofia no conhecimento técnico das ciências, parece ser um lançar-se de troca de saberes muito mais horizontal, ecológico e humanista, no sentido de respeitar os saberes, ter curiosidade e entrega por eles. Fazer o movimento de adentrar e se apropriar de conhecimentos distantes e trazê-los a sua proximidade, para que então, o estudante de um conhecimento também distante possa ter o gosto pela filosofia e pela sua própria ciência "como estética da inteligência". Esse parece ser o verdadeiro sentido dessa experiência narrada nesse artigo.

\begin{abstract}
A tipologia regional e mapear o potencial não só é um "protótipo técnico" cujo uso permitiria clarificar imperfeições. Estas são ferramentas reais para uma abordagem científica para a agricultura, [...]Os Obstáculos para o conhecimento quantitativo pelos agrônomos surgem a partir da variedade de relatórios daqueles que ele pode construir como suas hipóteses de compreender os componentes implicados em problemas de fertilidade serão justificados no apelo que façamos a ele. O ensino torna-se uma espécie de uma contribuição ao conhecimento, uma regra indispensável. (HERVÉ, 1997,p. 77)
\end{abstract}

Tal experiência da visão de Bachelard para as ciências agrárias já havia efetivamente sido feira na França por professores e agrônomos como Stéphane Henin e Michel Sebillotte, fortalecidos e aprofundados pela iniciativa do discípulo de Bachelard, François Dagognet. Pensadores que precisam ser mais difundidos e traduzidos no Brasil, já que se constitui verdadeiramente numa nova área de pesquisa na inter-relação da filosofia com as ciências agrárias.

\title{
REFERÊNCIAS
}

\footnotetext{
${ }^{4}$ Como a natureza foi um dos principais objetos da pesquisa da filosofia nas disciplinas propostas aos cursos, nada melhor do que o próprio Bachelard explicar o sentido dessa expressão espinosana "Aos nossos olhos, a humanidade imaginante é um além da natureza naturante. Só o enxerto pode dar realmente à imaginação material a exuberância das formas. É o enxerto que pode transmitir à imaginação formal a riqueza e a densidade das matérias. Obriga a planta selvagem a florescer e dá matéria à flor." (Bachelard, 1998, p. 11). Ora, não é no enxerto que justamente começa a técnica agronômica?
}

Dialektiké, v. 2, 2016. p. 10-18 
BACHELARD, Gaston. A formação do espírito científico. Trad. Estela Abreu. Rio de Janeiro: Contraponto, 1996.

A água e os sonhos. São Paulo: Martins Fontes, 1998.

A terra e os devaneios da vontade. São Paulo: Martins Fontes, 2001.

DAGOGNET, F. Des révolutions vertes. Histoire et principes de V agronomie, Paris, Hermann, 1973

HERVÉ, Jean Jacques. Bachelard et l'agronomie. IN: NOUVEL, Pascal. Actualité et posterités de Gaston Bachelard. Paris: Presses Universitaires de France, 1997.

LECOURT, Dominique. Comment boire une métaphore? IN: NOUVEL, Pascal. Actualité et posterités de Gaston Bachelard. Paris: Presses Universitaires de France, 1997.

LIBIS, Jean. Bachelard et le vin. IN: NOUVEL, Pascal. Actualité et posterités de Gaston Bachelard. Paris: Presses Universitaires de France, 1997.

ROUPNEL, Gaston. Sixième Partie - La Vigne. IN: Histoire de la campagne française. Paris: Graset, 1932. pp. 184-195.

SCRUTON, Roger. Bebo, Logo Existo. Trad. Cristina Cupertino. São Paulo: Octavo, 2011. 